\title{
PARAMETRIC OPTIMIZATION OF WIRE ELECTRICAL DISCHARGE MACHINING USING TOPSIS METHOD
}

\author{
Gadakh, V. S.* \\ *Department of Mechanical Engineering, Amrutvahini College of Engineering, Sangamner, \\ Ahmednagar, Maharashtra- 422 608, India \\ E-mail: gadakh_vijay@mec.vnit.ac.in
}

\begin{abstract}
:
In this paper, application of techniques for order preference by similarity to ideal solution (TOPSIS) method is applied for solving multiple criteria (objective) optimization problem in wire electrical discharge machining (WEDM) process. Three examples are included to illustrate the approach. In all the cases, it is found that, the results obtained using the TOPSIS method almost match with those derived by the past researchers which prove the applicability of this method while solving various complex decision-making problems in present day manufacturing environment.
\end{abstract}

Key Words: Multi-Objective Optimization, WEDM Process, TOPSIS, Decision-Making, Process Parameter, MADM

\section{INTRODUCTION}

Wire Electro Discharge machining (WEDM) is one of the important non-traditional machining processes which are used for machining difficult to machine materials like composites and inter-metallic materials. Intricate profiles used in prosthetics, bio-medical applications can also be done in WEDM. WEDM involves complex physical and chemical process including heating and cooling. The electrical discharge energy affected by the spark plasma intensity and the discharging time will determine the crater size, which in turn will influence the machining efficiency and surface quality [1]. The selection of optimum machining parameters in WEDM is an important step. Improperly selected parameters may result in serious problems like short-circuiting of wire, wire breakage and work surface damage which is imposing certain limits on the production schedule and also reducing productivity. As Material Removal Rate (MRR), Surface Roughness $\left(R_{a}\right)$ and kerf width $(k)$ are most important responses in WEDM; various investigations have been carried out by several researchers for improving the MRR, Surface Finish and kerf width. However, the problem of selection of machining parameters is not fully depending on machine controls rather material dependent [2]. A suitable selection of machining parameters for the electrical discharge machining process relies heavily on the operators' technologies and experience because of their numerous and diverse range. Machining parameters tables provided by the machine tool builder cannot meet the operators' requirements, since for an arbitrary desired machining time for a particular job; they do not provide the optimal machining conditions [3].

A good amount of research has been done in this area for optimal process parameter selection. But mostly the previous researchers have concentrated on a single response problem rather considering multi-response problem. The optimal parametric settings with respect to different performance characteristics are different. The selection of the best combination of the process parameters for an optimal machining performance involves analytical and statistical methods. Kuriakose and Shunmugam [4] have prepared a multiple regression model used to represent relationship between input and output variables and a multi-objective optimization method based on a Non-Dominated Sorting Genetic Algorithm (NSGA) used to optimize Wire-EDM process. Lin and Lin [5] have used grey-fuzzy logic based on orthogonal array for optimizing the electrical discharge machining process with 
multi-response characteristics. Mahapatra and Patnaik [6] have considered metal removal rate (MRR), surface finish (SF) and cutting width (kerf) as performances to solve multiresponse optimization problem using Taguchi method first and secondly using Genetic Algorithm.

Mandal, et al. [7] modeled EDM process using back propagation NN and multi-objective optimization using NDGA-II. Tzeng and Chen [8] have applied fuzzy logic analysis coupled with Taguchi method to optimize the precision and accuracy of the high-speed electrical discharge machining (EDM) process. Salman and Kayacan [9] have studied SR characteristics of different electrode material and prepared a SR model using genetic expression programming (GEP). Rao, et al. [10] have developed a hybrid model based on ANN and GA methodology to optimize the EDM process. Jangra, et al. [11] used grey relational analysis (GRA) along with Taguchi method for simultaneous optimization of MRR and SR for WEDM of WC-Co composite. Rao and Pawar [12] have prepared a mathematical model using Response Surface Methodology (RSM) and optimal parameter setting using Particle Swarm Optimization (PSO) algorithm. Shandilya, et al. [13] have considered single response problem i.e. SR and was solved using RSM and Analysis of Variance (ANOVA). Gadakh and Shinde [14] have used graph theory and matrix approach (GTMA) for selecting suitable process parameters in side milling. Also, they have applied few multiple attribute decision-making (MADM) methods to rank and select the process parameters. In this paper, an attempt is made to apply TOPSIS method for optimal process parameters selection in WEDM process. It is observed that in comparison to other methods, like ANN, GA, Taguchi method, grey-Taguchi method, grey relational analysis (GRA), the TOPSIS method is very simple and easy to implement. As this method may be quite useful and helpful to the decision makers, who may not have a strong background in mathematics. Also, the computation time of the TOPSIS method would obviously be less.

\section{TECHNIQUES FOR ORDER PREFERENCE BY SIMILARITY TO IDEAL SOLUTION (TOPSIS) METHOD}

The TOPSIS method was developed by Hwang and Yoon [15]. The method is based on the concept that the chosen alternative should have the shortest Euclidean distance from the ideal solution, and the farthest from the negative ideal solution. The ideal solution is a hypothetical solution for which all attribute values correspond to the maximum attribute values in the database comprising the satisfying solutions; the negative ideal solution is the hypothetical solution for which all attribute values correspond to the minimum attribute values in the database. TOPSIS thus gives a solution that is not only closest to the hypothetically best, that is also the farthest from the hypothetically worst.

Rao [16] have used this method various application such as: material selection, evaluation of product designs, machinability evaluation, cutting fluid selection, evaluation and selection of modern machining methods, machine selection, robot selection, selection of an automated inspection system, selection of material handling equipment, selection of rapid prototyping process in rapid product development, welding process selection for a given application, geometric moldability analysis of parts, evaluation of metal stamping layouts, selection of forging conditions for forging a given component, evaluation of environmentally conscious manufacturing programs, environmental impact assessment of manufacturing processes, evaluation of aggregate risk in green manufacturing, selection of best product end-of-life scenario, integrated project evaluation and selection, facility location selection, operational performance evaluation of competing companies, vendor selection in a supply chain environment, etc.

\subsection{Example 1}

Muthu Kumar, et al. [2] have optimized WEDM process parameters of Incoloy 800 super alloy with multiple performance characteristics such as Material Removal Rate (MRR), surface roughness $\left(R_{a}\right)$ and Kerf $(k)$ based on the Grey-Taguchi Method. In this work, 
considered process parameters are as: Gap Voltage (A), Pulse On-time (B), Pulse Off-time (C) and Wire Feed (D) and Taguchi's L9 Orthogonal Array was used to conduct the experiments. Now, the given problem is solved using TOPSIS method.

Table I: Quantitative data of the factors of example 1 Muthu Kumar, et al. [2].

\begin{tabular}{|c|c|c|c|c|c|c|c|}
\hline \multirow{2}{*}{ Exp. No. } & \multicolumn{5}{|c|}{ Control Factors } & \multicolumn{3}{c|}{ Responses } \\
\cline { 2 - 8 } & $\mathrm{A}$ & $\mathrm{B}$ & $\mathrm{C}$ & $\mathrm{D}$ & $\begin{array}{c}\text { MRR } \\
(\mathrm{g} / \mathrm{min})\end{array}$ & $\mathrm{R}_{\mathrm{a}}(\mu \mathrm{m})$ & $\mathrm{K}(\mathrm{mm})$ \\
\hline 1 & 1 & 1 & 1 & 1 & 0.04833 & 3.11 & 0.317 \\
\hline 2 & 1 & 2 & 2 & 2 & 0.05351 & 3.31 & 0.324 \\
\hline 3 & 1 & 3 & 3 & 3 & 0.05128 & 3.6 & 0.299 \\
\hline 4 & 2 & 1 & 2 & 3 & 0.04192 & 3.67 & 0.33 \\
\hline 5 & 2 & 2 & 3 & 1 & 0.04295 & 3.97 & 0.322 \\
\hline 6 & 2 & 3 & 1 & 2 & 0.05011 & 4.04 & 0.343 \\
\hline 7 & 3 & 1 & 3 & 2 & 0.03844 & 4.11 & 0.356 \\
\hline 8 & 3 & 2 & 1 & 3 & 0.03974 & 4.26 & 0.368 \\
\hline 9 & 3 & 3 & 2 & 1 & 0.04538 & 4.4 & 0.376 \\
\hline
\end{tabular}

The procedure of the TOPSIS method for the selection of the best alternative from among those available alternatives is as:

Step 1: The objective is to evaluate the nine alternatives, and the attributes are: $M R R, R_{a}$ and $\mathrm{k}$. For this particular problem, MRR is considered as beneficial attribute (i.e. higher values); While $R_{a}$ and $k$ are considered as non-beneficial (i.e. smaller values).

Step 2: The next step is to represent all the information available for the attributes in the form of a decision matrix. The data given in Table I are represented as matrix $D_{9 \times 3}$. However, the matrix is not shown here, due to space reason, as it is simply the repetition of data given in Table I but represented in a matrix form.

Step 3: The quantitative values of the WEDM performance selection factors (WPSF), which are given in Table I, are normalized and the normalized matrix $R_{9 \times 3}$ is shown in Equitation 1 :

$$
R_{9 \times 3}=\left|\begin{array}{lll}
0.1174 & 0.0902 & 0.1044 \\
0.1299 & 0.0960 & 0.1067 \\
0.1245 & 0.1044 & 0.0985 \\
0.1018 & 0.1064 & 0.1087 \\
0.1043 & 0.1151 & 0.1060 \\
0.1217 & 0.1172 & 0.1130 \\
0.0933 & 0.1192 & 0.1172 \\
0.0965 & 0.1235 & 0.1212 \\
0.1102 & 0.1276 & 0.1238
\end{array}\right|
$$

Step 4: Relative importance of attributes $\left(R_{i j}\right)$ can be assigned the values. And the weights considered are: $M R R=0.5 ; R_{a}=0.3$ and $k=0.2$. However, the weights considered are for demonstration purpose only. The decision maker can take any value but the sum of the weights should be one.

Step 5: The weighted normalized matrix, $\mathrm{V}_{9 \times 3}$, is calculated Equitation 2. 


$$
V_{9 \times 3}=\left|\begin{array}{ccc}
0.0587 & 0.0270 & 0.0208 \\
0.0649 & 0.0288 & 0.0213 \\
0.0622 & 0.0313 & 0.0197 \\
0.0509 & 0.0319 & 0.0217 \\
0.0521 & 0.0345 & 0.0212 \\
0.0608 & 0.0351 & 0.0226 \\
0.0466 & 0.0357 & 0.0234 \\
0.0482 & 0.0370 & 0.0242 \\
0.0551 & 0.0382 & 0.0247
\end{array}\right|
$$

Step 6: The next step is to obtain the ideal (best) and negative ideal (worst) solution. These are calculated as:

$$
\begin{aligned}
& V_{M R R}^{+}=0.1299 V_{R_{a}}^{+}=0.0902 V_{k}^{+}=0.0985 \\
& V_{M R R}^{-}=0.0933 V_{R_{a}}^{-}=0.1276 V_{k}^{-}=0.1238
\end{aligned}
$$

Step 7: The next step is to obtain the separation measures, and these are calculated as:

$$
\begin{array}{ll}
S_{1}^{+}=0.0153 & S_{1}^{-}=0.0219 \\
S_{2}^{+}=0.0142 & S_{2}^{-}=0.0210 \\
S_{3}^{+}=0.0145 & S_{3}^{-}=0.0210 \\
S_{4}^{+}=0.0157 & S_{4}^{-}=0.0213 \\
S_{5}^{+}=0.0153 & S_{5}^{-}=0.0209 \\
S_{6}^{+}=0.0137 & S_{6}^{-}=0.0198 \\
S_{7}^{+}=0.0157 & S_{7}^{-}=0.0207 \\
S_{8}^{+}=0.0152 & S_{8}^{-}=0.0201 \\
S_{9}^{+}=0.0139 & S_{9}^{-}=0.0192
\end{array}
$$

Step 8: The relative closeness of a particular alternative to the ideal solution is calculated and these are:

$$
\begin{array}{lll}
P_{1}=0.5881 & P_{2}=0.5975 & P_{3}=0.5926 \\
P_{4}=0.5755 & P_{5}=0.5765 & P_{6}=0.5901 \\
P_{7}=0.5678 & P_{8}=0.5696 & P_{9}=0.5800
\end{array}
$$

This relative closeness to ideal solution can be considered as the WEDM performance suitability index (WPSI).

Step 9: The alternatives are arranged in descending order of their WPSI. This can be arranged as:

\section{2-3-6-1-9-5-4-8-7.}

From these values of index, it is understood that the WEDM process parameter designated as alternative 2 is the first right choice; alternative 3 , the second choice; and alternative 7, the last choice for the given application under the given conditions. The optimal WEDM process parameters relative to alternative 2 are as: Gap Voltage (A), 50 Volts; Pulse 
ON Time (B), $8 \mu \mathrm{s}$; Pulse OFF Time (C), $6 \mu \mathrm{s}$, and Wire Feed (D), $8 \mathrm{~mm} / \mathrm{min}$; MRR, $\mathrm{R}_{\mathrm{a}}$ and $\mathrm{k}$ are: $0.05351 \mathrm{~g} / \mathrm{min}, 3.31 \mu \mathrm{m}$ and $0.324 \mathrm{~mm}$ respectively.

These results match those suggested by Muthu Kumar, et al. [2] using orthogonal array with gray-Taguchi method. Muthu Kumar, et al. [2] have obtained same process parameter using orthogonal array only change in the Pulse ON Time (B), $10 \mu$ s using gray theory design. However, it may be mentioned that the ranking depends upon the judgements of relative importance made by the designer. The ranking presented may change if the designer assigns different relative importance values to the attributes.

\subsection{Example 2}

Shandilya, et al. [13] have used response surface methodology (RSM) to study the effect of wire electric-discharge cutting (WEDC) of $10 \%$ SiCp/ Aluminum 6061 metal matrix composite (MMC) input process parameters and surface roughness. In this study, considered process parameters are same in the example 1 as: Gap Voltage (A), Pulse On-time (B), Pulse Offtime (C) and Wire Feed (D). The SR is the only single performance characteristic which is considered as non-beneficial (i.e. smaller values) as shown in Table II. They have obtained the results as: SR, $1.761 \mu \mathrm{m}$. The process parameters relative to the SR are: $71.01 \mathrm{~V}$ as voltage, $1.00 \mu \mathrm{s}$ as pulse-on time, $6.04 \mu \mathrm{s}$ as pulse off time and $5.17 \mathrm{~m} / \mathrm{min}$ wire feed rate.

Table II: Quantitative data of the factors of example 2 Shandilya, et al. [13].

\begin{tabular}{|c|c|c|c|c|c|}
\hline Exp. No. & A & B & C & D & $\mathrm{R}_{\mathrm{a}}$ \\
\hline 1 & 0 & 1 & 0 & -1 & 2.3 \\
\hline 2 & -1 & 0 & 0 & -1 & 1.78 \\
\hline 3 & 0 & 0 & 1 & 1 & 2.05 \\
\hline 4 & -1 & 0 & 1 & 0 & 1.8 \\
\hline 5 & 0 & -1 & -1 & 0 & 1.92 \\
\hline 6 & 1 & 0 & 0 & -1 & 2.92 \\
\hline 7 & 1 & 0 & -1 & 0 & 2.88 \\
\hline 8 & 0 & 0 & 0 & 0 & 2.12 \\
\hline 9 & 0 & 0 & 0 & 0 & 2.02 \\
\hline 10 & 1 & 0 & 0 & 1 & 2.72 \\
\hline 11 & 0 & 0 & 1 & -1 & 2.06 \\
\hline 12 & 0 & 0 & 0 & 0 & 2.04 \\
\hline 13 & 0 & -1 & 0 & 1 & 1.95 \\
\hline 14 & 0 & 0 & 0 & 0 & 2.35 \\
\hline 15 & 0 & 1 & 0 & 1 & 2.32 \\
\hline 16 & 0 & 0 & 0 & 0 & 2.16 \\
\hline 17 & 1 & 0 & 1 & -1 & 2.86 \\
\hline 18 & 0 & 1 & -1 & -1 & 2.5 \\
\hline 19 & 0 & 0 & -1 & 1 & 2.22 \\
\hline 20 & 0 & -1 & 0 & -1 & 1.98 \\
\hline 21 & 0 & 0 & -1 & -1 & 2.54 \\
\hline 22 & 0 & -1 & 1 & 0 & 1.89 \\
\hline 23 & 1 & 1 & 0 & 0 & 3.08 \\
\hline 24 & -1 & 0 & -1 & 0 & 1.85 \\
\hline 25 & -1 & 1 & 0 & 0 & 1.87 \\
\hline 26 & -1 & 0 & 0 & 1 & 2.26 \\
\hline 27 & -1 & -1 & 0 & 0 & 1.77 \\
\hline 28 & 1 & -1 & 0 & 0 & 2.7 \\
\hline 29 & 0 & 1 & 1 & 0 & 2.26 \\
\hline & & & & & \\
\hline
\end{tabular}


However, from the Table II, the decision maker can directly select the lowest value of the $R_{a}$, $1.77 \mu \mathrm{m}$ without applying any statistical tool or method. In general, for any one alternative having all the attributes or factors are either beneficial or non-beneficial in nature. In that case that alternative candidate is the first or best choice for the given application. i.e. no need to apply any other method. Also, for single performance characteristic the designer can directly select the cutting or process parameters by considering beneficial (i.e. higher values) and non-beneficial (i.e. smaller values) attributes without use of any methodology or tool. e.g. If TWR is only the performance characteristic then designer can select lower value of TWR and corresponding values give optimal values of parameters.

\subsection{Example 3}

Balasubramanian and Ganapathy [1] have studied multiple performance characteristics such as MRR and SR based on the Grey Relational Analysis (GRA) to optimize process parameters for WEDM. In this work, six control factors considered are as: Gap Voltage (A), Pulse On-time (B), Pulse Off-time (C), Applied Current (D), Wire tension (E) and Wire feed rate $(F)$ as shown in Table III.

Table III: Quantitative data of the factors of example 3 Balasubramanian and Ganapathy (2011).

\begin{tabular}{|c|c|c|c|c|c|c|c|c|}
\hline $\begin{array}{c}\text { Exp. } \\
\text { No. }\end{array}$ & A & B & C & D & E & F & Avg. $R_{a}$ & $\begin{array}{c}\text { Avg. } \\
\text { MRR }\end{array}$ \\
\hline 1 & 1 & 1 & 1 & 2 & 2 & 2 & 2.366667 & 26.33333 \\
\hline 2 & 2 & 2 & 2 & 1 & 2 & 1 & 2.233333 & 28 \\
\hline 3 & 1 & 3 & 3 & 2 & 1 & 2 & 2.466667 & 32 \\
\hline 4 & 2 & 4 & 4 & 1 & 1 & 1 & 2.316667 & 32.66667 \\
\hline 5 & 1 & 4 & 1 & 2 & 2 & 2 & 2.366667 & 32.66667 \\
\hline 6 & 2 & 3 & 2 & 1 & 2 & 1 & 2.6 & 29.33333 \\
\hline 7 & 1 & 2 & 3 & 2 & 1 & 2 & 2.6 & 34 \\
\hline 8 & 2 & 1 & 4 & 1 & 1 & 1 & 2.566667 & 32.33333 \\
\hline
\end{tabular}

In this study, MRR is considered as beneficial attribute (i.e. higher values); While SR is considered as non-beneficial (i.e. smaller values). The weights assumed to be considered for MRR and SR are 0.5 equally. By applying TOPSIS method, the results obtained are same as

Table IV: weighted normalized data for example 3.

\begin{tabular}{|c|c|c|}
\hline $\begin{array}{c}\text { Exp. } \\
\text { No. }\end{array}$ & SR & MRR \\
\hline 1 & 0.0606 & 0.0532 \\
\hline 2 & 0.0572 & 0.0566 \\
\hline 3 & 0.0631 & 0.0646 \\
\hline 4 & 0.0593 & 0.0660 \\
\hline 5 & 0.0606 & 0.0660 \\
\hline 6 & 0.0666 & 0.0592 \\
\hline 7 & 0.0666 & 0.0687 \\
\hline 8 & 0.0657 & 0.0653 \\
\hline
\end{tabular}


Table V: Separation measures for example 3.

\begin{tabular}{|c|c|c|}
\hline Exp. No. & $S_{i}^{+}$ & $S_{i}^{-}$ \\
\hline 1 & 0.0606 & 0.0532 \\
\hline 2 & 0.0572 & 0.0566 \\
\hline 3 & 0.0631 & 0.0646 \\
\hline 4 & 0.0593 & 0.0660 \\
\hline 5 & 0.0606 & 0.0660 \\
\hline 6 & 0.0666 & 0.0592 \\
\hline 7 & 0.0666 & 0.0687 \\
\hline 8 & 0.0657 & 0.0653 \\
\hline
\end{tabular}

The ideal (best) and negative (worst) solution is then calculated as:

$$
\begin{array}{ll}
V_{M R R}^{+}=0.1374 & V_{S R}^{+}=0.1144 \\
V_{M R R}^{-}=0.1064 & V_{S R}^{-}=0.1332
\end{array}
$$

In the next step relative closeness of a particular alternative to the ideal solution is calculated and these are:

$$
\begin{array}{llll}
P_{1}=0.4478 & P_{2}=0.4571 & P_{3}=0.4563 & P_{4}=0.4656 \\
P_{5}=0.4633 & P_{6}=0.4423 & P_{7}=0.4553 & P_{8}=0.4519
\end{array}
$$

The alternatives are arranged in descending order of their WPSI. This can be arranged as:

\section{4-5-2-3-7-8-1-6.}

From these values of index, it is understood that the WEDM process parameter designated as alternative 4 is the first right choice; alternative 5 , the second choice; and alternative 6 , the last choice for the given application under the given conditions. The optimal WEDM process parameters relative to alternative 4 are as: Gap Voltage (A), 15 Volts; Pulse ON Time (B), $4.4 \mu \mathrm{s}$; Pulse OFF Time (C), $10 \mu \mathrm{s}$, Applied Current (D), 8 A, Wire tension (E), $6 \mathrm{~N}$ and Wire feed rate $(\mathrm{F}), 5 \mathrm{~m} / \mathrm{min}$; MRR, and SR are: $32.6666 \mathrm{~mm}^{3} / \mathrm{min}, 2.3166 \mu \mathrm{m}$ respectively.

These results match those suggested by Balasubramanian and Ganapathy [1] using Gray Relational Analysis (GRA). Balasubramanian and Ganapathy [1] have obtained same process parameter using GRA only change in the Applied Current (D), 12 A.

From the above discussions, it can be concluded that for the three considered decision making problems, the TOPSIS method fulfils almost all the conditions as cited by Hwang and Yoon [15], and hence, this method would be quite robust under diverse manufacturing environment.

\section{CONCLUSIONS}

The method represents selection of optimal process parameters in WEDM process using TOPSIS method. The suggested methodology can be used for any type of selection problem involving any number of selection criteria. Three illustrative examples are considered to demonstrate the application and validated using TOPSIS method. In all the cases, it is observed that the top-ranked alternatives exactly match with those suggested by previous researchers. The TOPSIS method can consider all the attributes along with their relative importance, and hence, it can provide a better accurate evaluation of the alternatives. This method is computationally very simple, easily comprehendible, and robust which can simultaneously consider any number of quantitative and qualitative selection attributes, while offering a more objective and logical selection approach. Application of this method in a 
wider range of selection problems in real-time environment remains as a future research scope of this paper.

\section{REFERENCES}

[1] Balasubramanian, S.; Ganapathy, S. (2011). Grey Relational Analysis to Determine Optimum Process Parameters for Wire Electro Discharge Machining (WEDM). International Journal of Engineering Science and Technology, Vol. 3, No. 1, 95-101, ISSN: 0975-5462

[2] Muthu Kumar, V.; Suresh Babu, A.; Venkatasamy, R.; Raajenthiren, M. (2010). Optimization of the WEDM Parameters on Machining Incoloy 800 Super alloy with Multiple Quality Characteristics, International Journal of Engineering Science and Technology, Vol. 2, No. 6, 1538-1547

[3] Thillaivanan, A.; Asokan, P.; Srinivasan, K.N.; Saravanan, R. (2010). Optimization of operating parameters for EDM process based on the taguchi method and artificial neural network. International Journal of Engineering Science and Technology, Vol. 2, No. 12, 6880-6888, ISSN: 0975-5462

[4] Kuriakose, S.; Shunmugam, M. S. (2005). Multi-objective optimization of wire-electro discharge machining process by Non-Dominated Sorting Genetic Algorithm, Journal of Materials Processing Technology, Vol. 170, No. 1-2, 133-141, doi:10.1016/j.jmatprotec.2005.04.105

[5] Lin, J.L.; Lin, C.L. (2005). The use of grey-fuzzy logic for the optimization of the manufacturing process, Journal of Materials Processing Technology, Vol. 160, No. 1, 9-14, doi:10.1016/j.jmatprotec.2003.11.040

[6] Mahapatra, S. S.; Patnaik, A. (2006). Optimization of wire electrical discharge machining (WEDM) process parameters using Taguchi method, International Journal of Advanced Manufacturing Technology, Vol. 34, No. 9-10, 911-925, doi: 10.1007/s00170-006-0672-6

[7] Mandal, D.; Pal, S. K.; Saha, P. (2007). Modeling of electrical discharge machining process using back propagation neural network and multi-objective optimization using non-dominating sorting genetic algorithm-II, Journal of Materials Processing Technology, Vol. 186, No. 1-3, 154-162, doi:10.1016/j.jmatprotec.2006.12.030

[8] Tzeng, Y. F.; Chen, F. C. (2007). Multi-objective optimization of high-speed electrical discharge machining process using a Taguchi fuzzy-based approach, Materials and Design, Vol. 28, No. 4, 1159-1168, doi:10.1016/j.matdes.2006.01.028

[9] Salman, O.; Kayacan, M. C. (2008). Evolutionary programming method for modeling the EDM parameters for roughness, Journal of Materials Processing Technology, Vol. 200, No. 1-3, 347-355, doi:10.1016/j.jmatprotec.2007.09.022

[10] Rao, G. K. M.; Rangajanardhaa, G.; Rao, D. H.; Rao, M. S. (2009). Development of hybrid model and optimization of surface roughness in electric discharge machining using artificial neural networks and genetic algorithm, Journal of Materials Processing Technology, Vol. 209, No. 3, 1512-1520, doi:10.1016/j.jmatprotec.2008.04.003

[11] Jagra, K.; Jain, A.; Grover, S. (2010). Optimization of multiple-machining characteristics in wire electrical discharge machining of punching die using Grey Relational Analysis, Journal of Scientific and Industrial Research, Vol. 69, No. 8, 606-612

[12] Rao, R. V.; Pawar, P. J. (2010). Process parameters modeling and optimization of wire electric discharge machining. Advances in Production Engineering and Management, Vol. 5, No. 3, 139-150, ISSN-1854-6250

[13] Shandilya, P.; Jain, P. K.; Jain, N. K. (2011). Modeling and Analysis of Surface Roughness in WEDC of SiCP 6061 Al MMC through response surface methodology. International Journal of Engineering Science and Technology, Vol. 3, No. 1, 531-535, ISSN: 0975-5462

[14] Gadakh, V. S.; Shinde, V. B. (2011). Selection of cutting parameters in side milling operation using graph theory and matrix approach. International Journal of Advanced Manufacturing Technology, doi: 10.1007/s00170-011-3256-z

[15] Yoon, K. P.; Hwang, C. L. (1995). Multiple attribute decision making. SAGE Publications, Beverly Hills, CA

[16] Rao, R. V. (2007). Decision Making in the Manufacturing Environment Using Graph Theory and Fuzzy Multiple Attribute Decision Making Methods. Springer-Verlag, London 